\title{
Tendências da Língua Coloquial Observadas nos "Erros" Em Trabalhos Escolares
}

\author{
Maria Lucia Mexias-Simon \\ Universidade Severino Sombra, Centro de Letras, Ciências Sociais \\ Aplicadas e Humanas, Curso de Letras, mmexiassimon@yahoo.com.br
}

Resumo: Análise dos erros mais frequentes na grafia, na morfologia e na sintaxe, encontrados em redações de alunos do $2^{\circ}$. segmento do Ensino Fundamental, como indicadores de tendências linguísticas em dadas regiões e faixa etária.

Palavras-chave: Língua Portuguesa. Ensino de Língua. Sociolingüística.

\section{Linguistics Trends in Analysis of "Errors" in Compositions of Students}

\begin{abstract}
Abstract: Analysis of most frequent errors in spelling, morphology and syntax found in compositions students in the 2nd segment of primary education, as indicators of trends in given linguistic regions and age groups.
\end{abstract}

Keywords: Portuguese Language. Language Teaching. Sociolinguistics.

\section{Apresentação}

No presente artigo pretende-se citar e comentar alguns dos erros encontrados em redações de nossos escolares, na faixa de 11 a 18 anos, exatamente a fase que os sociolinguistas tomam como o momento decisivo.

Inicialmente será feita a descrição geográfica do município de Vassouras-RJ onde foi colhido o corpus assim como da localidade onde fica a escola. Serão, também, apresentados alguns informes sobre o estrato social a que pertencem os escolares cujos trabalhos foram considerados. 
Após a citação, por vezes com sua frequência, dos erros assinalados, tentar-se-á apreciálos como sintoma da deriva linguística.

Para a recolha do corpus procedeu-se da seguinte forma: às turmas de $5^{\mathrm{a}}$.e $6^{\mathrm{a}}$. séries (total 55 alunos) foi solicitado que transcrevessem a historia da vida de Santa Rita de Cássia. Essa biografia é bastante conhecida dos alunos, por ser Santa Rita a padroeira da localidade e da escola, cujo prédio foi construído na mesma praça onde fica a Igreja em devoção à santa. As redações foram feitas na semana dos festejos em louvor a Santa Rita, quando são mais frequentemente mencionados os seus dados biográficos em missas, procissões com cânticos etc. Entre os alunos de outras religiões, apenas uma menina mostrou, resistência, sendo a ela sugerido não usar a palavra santa, de vez que sobre a existência histórica de Rita de Cássia não há dúvida.

Aos alunos da $7^{\mathrm{a}}$ serie foi solicitado que redigissem um mini-estatuto composto do cinco deveres e cinco direitos para os alunos, Esses tema veio à baila por estarem os jovens muito envolvidos, nessa altura, com a problemática da Constituinte.

Que o exame dos erros escolares deveria constituir um valiosíssimo método de investigação para o dialetólogo e que suas conclusões podem ser de capital importância para o educador, já afirma Rona no Simpósio de Cartagena [Rona, 1960, 341-342].

Frisava ainda, anteriormente, o mestre Rona;

\footnotetext{
... desde el punto do vista teórico qualquer fenómeno linguistico interessa a investigacion dialetal... la importância radica aqui en la incidência del fenómeno on el cuadro total de la realidad linguistica... en oiro plano, es "importante" todo fenómeno que puede servir de base para explicar o interpretar otros fenómenos. (Rona, 1958, 22-23)

Mattoso Camara tem como "erro" a "mudança", da qual se tem uma clara noção, pois colide com os centros da linguagem solidamente organizados numa comunidade linguistica [Camara, 1964, 195]
}

Desses erros, os mais sentidos são os do campo fonético. A evolução geral da língua, via de regra, toma impulso nas mudanças fonéticas. Essas mudanças, cujas causas só prendem a fatores extra e intralingüísticos, refletem-se em flutuações ortográficas, já por não haver correspondência entre o sistema de fonemas e o sistema de grafemas, já por o sistema de grafemas corresponder a um sistema fonêmico diferente do falar local. As hesitações entre as diversas realizações no campo fonético acabam por se estender às flexões e, ate mesmo, à sintaxe como se pretende demonstrar neste artigo.

\section{Caracterização do Município}

Nome - Vassouras

Origem do nome - "vassoura" planta da família das escrofularíneas também chamada tupeiçava ou vassourinha de varrer, (Dic. Caldas AULETE). Essa planta é abundante na região.

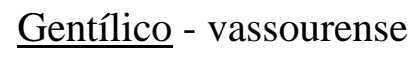

Mosaico - Revista Multidisciplinar de Humanidades, Vassouras, v. 1, n. 2, p. 11-20, jul./dez., 2010 
Dossiê Temático: Cultura, Civilização e Cidadania

Data da_oCUPAÇÃO: - fins do século XVII por Garcia Rodrigues Pais e seus descendentes.

Data de criação do município: - 29 de setembro de lô57

Principal atividade econômica - agro-pecuáría

Número de habitantes -44.322 - $43 \%$ na zona urbana, $57 \%$ na zona rural (segundo último censo)

$\underline{\text { Superfície }}-864 \mathrm{~km}^{2}$ - $\underline{\text { Altitude }}-416 \mathrm{~m}$

Localidade

O bairro Madruga (origem do nome desconhecida), onde estava localizada a Escola Estadual Santa Rita, fica a cerca do dois quilômetros do centro comercial e administrativo do município e a cerca do meio quilômetro do perímetro urbano. $\mathrm{O}$ bairro, outrora isolado, está, nos últimos anos, em processo de acelerado crescimento populacional. Esse fato observa-se na matrícula da Escola Santa Rita que de 150 alunos em 1966, passou a contar, em 1987, 560 alunos.

O único meio de transporte coletivo é o ônibus para as localidades vizinhas. As casas são, em sua maior parte, de alvenaria, servidas por luz elétrica e água encanada. Há comércio de gêneros de primeira necessidade. As ruas são, na maior parte, asfaltadas.

Não há áreas de lazer.

Estrato social

Entre os alunos cujos trabalhos estão sendo observados, colheram-se os seguintes dados:

$\underline{\text { Idade }}-11$ a 18 anos

Renda familiar:

- abaixo do salário mínimo - 33\%

- salário mínimo - 50\%

- de 1 a 2 salários mínimos - 50\%

- mais de 2 salários mínimos - 7\%

Obs.: levou-se em conta apenas a renda fixa declarada.

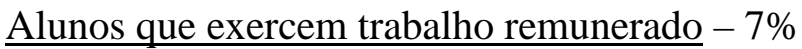

Naturalidade dos pais - 99\% fluminense

Grau de instrução dos pais

- analfabetos $-10 \%$

- primário incompleto- $20 \%$

- primário completo - $57 \%$ 
- $\quad$ secundário - $12 \%$

- superior $-1 \%$

Profissões mais declaradas (dos pais ou responsáveis)

- empregada doméstica - $10 \%$

- servente $-12 \%$

- motorista $-10 \%$

- empregado em construção civil - $10 \%$

- enfermeiro - 7\% (há dois hospitais nas proximidades)

- . jardineiro - $2 \%$

- aposentado $-2 \%$

Frequência aos meios de comunicação (pelos alunos e -familiares)

\begin{tabular}{|c|c|c|c|}
\hline & Sempre & Às vezes & Nunca \\
\hline cinema & $3 \%$ & $30 \%$ & $67 \%$ \\
\hline teatro & - & $2 \%$ & $98 \%$ \\
\hline jornal & $15 \%$ & $20 \%$ & $65 \%$ \\
\hline revista & $17 \%$ & $18 \%$ & $65 \%$ \\
\hline rádio e TV & $92 \%$ & $8 \%$ & - \\
\hline
\end{tabular}

\section{Exemplos concretos dos erros encontrados}

\section{$\underline{\mathrm{Na} \text { fonética - traduzidos na grafia }}$}

Abstraídos os casos de óbvia distração na escrita, encontramos, entre outros, os seguintes exemplos:

- hesitação na escolha entre grafemas com valor fônico igual ou próximo (assacino, Cacia, Casia, serto, realisou, resar, velhise, sicatriz, mossa por moça, sidadão, uniformisado, discuçao, puchar etc).

- vocalização do $/ \underline{1} /$ posvocálico (mau por mal); o erro mais frequente é o oposto, por 
Dossiê Temático:

Cultura, Civilização e Cidadania

supercorreção (melhorol, mal por mau, sendo que esse último aparece quinze vezes).

- desaparecimento da oposição entre /o/ e /i/, assim como /o/ o /u/ átonos (firida, madri, ajuelhou, crenti, deligência e caio por caiu, como supercorreção).

- omissão do/h/ inicial (ouve por houve, averá)

- omissão do /r/ final (faze por fazer)

- ausência de distinção entre há, e a. (viveu a anos)

- desaparecimento da oposição entre /ou/ e /o/ adianto por adiantou, professoures, como supercorreção)

- troca de surda por sonora (voi por foi)

- desaparecimento da oposição entre ditongo e vogal simples antes de fricativa chiante (deisde ou deis de, cruis, feis, mais por mas; este aparece sete vezes, o contrario, apenas uma vez)

\section{$\underline{\mathrm{Na} \text { morfologia }}$}

- Confusão entro pronome enclítico se e terminação do subjuntivo -sse (queriam que ela casa-se)

- perda da distinção antro os prefixos en- e in-, (inciumada.)

- nasalização da sílaba inicial i (e) (impidemia, insolada por isolada) por confusão com o prefixo im- , in-

- repudio ao pretérito imperfeito do subjuntivo (queriam que ela casava)

- perda da distinção entre terminação do pretérito perfeito e futuro do presente (brigarão por brigaram)

Na sintaxe:

- Enfraquecimento das desinências verbais, desaparecendo a concordância do verbo com o sujeito (os outros pratica, eles não aguentou)

- emprego artificialista do pronome acusativo pelo dativo (Deus os tirou os filhos aparece quatro vezes)

- emprego desnecessário do artigo (cujo o nome)

- abandono da preposição antes do conetivo que (cruz igual que Jesus levou)

- aparecimento da desinência no infinitivo, quando já aparece no verbo modal (devem•terem os direitos, devem serem tratados)

- queda do s desinência de plural no grupo de força em que o plural é indicado no determinativo (os aluno, duas menina, as nossa falta) - esse fato é muito frequente. 
Dossiê Temático:

Cultura, Civilização e Cidadania

\section{Apreciação dos erros como exemplos de tendências lingüísticas.}

\section{Na fonética}

Como já foi visto, a dúvida na representação do certos fonemas, deve-se a que o quadro de grafemas não corresponde a realidade linguística sintópica ou sincrônica. Isso só se dá quanto as fricativas palatais e as sibilantes. Em relação a essas ultimas, o sistema tônico mais conservador no norte de Portugal possui quatro sibilantes distintas; duas apico-alveolares, uma surda e uma sonora, e duas predorso-dentais, também uma surda e uma sonora, correspondendo, respectivamente, na grafia, ao /s/ inicial, /ss/ e ao /s/ intervocálico, por um lado, e, por outro lado, ao /ç/ ao /c/ (antes de /e/ e /i/) e ao /z/. É, aí, distinta a pronúncia, por exemplo, entre "coser" a roupa e "cozer" o pão. No sul de Portugal e em grande parte do centro, perdura somente a distinção surda/sonora, havendo apenas duas sibilantes predorso-dentais. A esse sistema pertence o português do Brasil. O sistema gráfico, mais resistente, continua marcando a distinção etimológica, o que já não existe na pronúncia. Quanto à aproximação do português do Brasil com o falar do sul de Portugal, explica o professor Serafim da Silva Noto, serem áreas colonizadas na mesma época (século XVI a XVIII). Como acontece em áreas colonizadas, formou-se uma espécie de falar médio dos colonizadores, uma simplificação de diferenças dialetais, pela necessidade de intercompreensão.

A generalização da vocalização do /l/ velar posvocálico em /u/ leva algumas pessoas, sobretudo os professores, por ocasião de leituras e ditados, a uma supercorreção, chegando a pronunciar o /1/ dental. Daí ser o /1/. pronunciado normalmente, interpretado como /u/. De tanto sofrer correções, o aluno segue o caminho oposto, grafando /l/ onde seria $/ \mathrm{u} /$.

$\mathrm{O}$ mesmo se pode dizer quanto à ausência de contraste entre /e/ e /i/ e entre /o/ e /u/ átonos. Quando desaparece a preocupação em manter a distinção, os alunos tendem a escrever como ouvem, sobretudo em palavras que não são de leitura muito frequente (caso de madre, epidemia). Ocorrem, também, nesse caso, supercorreções (epedemia e a estranha forma epdemia).

A falta do /h/ inicial deve-se, obviamente, a sua total perda do valor fônico, sendo muito comum a grafia ouve por houve já que ambas existem nas normas gramaticais. Não tão frequentes serão os outros casos de omissão do /h/ inicial.

A queda do /r/ final, tão frequente, é tida por diversos autores como típica da linguagem coloquial do Rio de Janeiro. Deve -se notar que esse esvaimento é menos comum no final das frases e muito menos comum em nomes próprios.

A ausência da distinção de /a/ átono em aberto e fechado, existente em Portugal leva os alunos a duas soluções, também influenciados por pronúncias artificialistas: a não marcação do /a/ craseado, quando da leitura normal, ou o emprego do acento grave e da forma há para simples preposição, quando o la/ é pronunciado mais fortemente, Encontram-se, ainda, marcados com acento grave, artigos e ate pronomes oblíquos a, as, por supercorreção. Esse fato é um dos que se pode observar mais freqüentemente. 
A monotongação do ditongo /ou/ em /o/ também teve seu foco de origem no sul de Portugal, dai irradiando-se para o norte. Essa foi a forma transplantada ao Brasil. Nosso caso, também, o esforço em manter o ditongo leva a supercorreções.

Quanto à troca de consoante surda por sonora, pode-se observar que isso ocorre quando a surda está em posição fraca no vocábulo ou no grupo de força. A articulação fraca prejudica a nítida percepção da presença ou ausência de sonoridade.

A ditongação da vogal diante de consoante chiante na mesma sílaba é também considerada como traço do falar carioca, onde chega a se realizar como um alofone palatal /j/. Tal realização foi aceita no Congresso de Língua Falada no Teatro, com o fundamento de que se encontra em falares portugueses. A poesia a consagra quando faz rimar por exemplo, luz com azuis, .jamais com voraz.

Ainda em relação ao corpus analisado, encontramos dignos de menção, um exemplo do que Mattoso Camara chama dissimilação - flera por freira - essa forma, onde aparece ainda a monotongação foi grafada por nada menos do que cinco alunos. Registre-se mais a estranha forma urmanidade, por urbanidade, na única redação que foi claramente copia do um texto literário (analogia com irmandade?).

\section{Na morfologia}

A linguagem coloquial rejeita o imperfeito do subjuntivo em certos contextos (substitui pelo imperfoito do indicativo) e dá preferência aos pronomes átonos proclíticos, inclusive o se apassivador ou reflexivo. Daí a não exata compreensão da terminação -sse do imperfeito do subjuntivo, grafada, as vezes, com hífen. Aparecem ainda no corpus as formas: matasem, sofrece, se casou-se e casouse, numa evidente perda da noção do flexão verbal e do valor do pronome enclítico.

A confusão entre os prefixos $i$, in, en (insolada, inciumada) pode-se atribuir a uma supercorreção ou a uma harmonização vocálica, no segundo caso. O fato pode se estender a i e o como sílabas iniciais (inpidemia - sic).

O futuro do presente, originado na forma perifrástica do latim vulgar, acabou por quase coincidir foneticamente, na $3^{\mathrm{a}}$. pessoa do plural, com o pretérito perfeito do indicativo. Resta a distinção apenas na tonicidade da última sílaba, presentes no primeiro caso, ausente no segundo. Como essa distinção quase se dilui num grupo de força, os alunos, sem muito treino ortográfico, tendem a confundir as duas formas, na escrita.

\section{$\underline{\text { Na sintaxe }}$}

Nota-se,com bastante frequência, a ausência da distinção singular/plural nas formas verbais na $3^{\mathrm{a}}$. pessoa. Pode-se dizer que a marca de pluralidade na forma verbal torna-se desnecessária por já aparecer no sujeito. Tal construção tendo a uma impessoalizaçao do verbo, deixando o sujeito de se sentido com tal.

O emprego do $\underline{\text { o, }}$ como pronome dativo só pode ser atribuído à supercorreção, uma vez que o mais comum na linguagem coloquial é o fato inverso (lhe como acusativo), 
Dossiê Temático:

havendo o pronome $\underline{\mathrm{o}}$, praticamente desaparecido da linguagem falada. Por ser um trabalho escolar uma situação mais tensa, houve um redescobrimento forçado do o, pronome, até mesmo abusivamente.

Também à supercorreção se deve a dupla flexão pessoal, no verbo modal e no infinitivo, (devemos fazermos) fenômeno inverso à perda de flexão, citada mais acima.

A ausência do s, desinência do plural, aparece quatro vezes no corpus. Esse fato relaciona-se com o primeiro aqui citado. Se a marca de plural já aparece no determinativo, é sentida como desnecessária no substantivo. Como se esvaíram as desinências casuais no latim, por perda da funcionalidade, talvez haja uma deriva para o apagamento da desinência plural. Esse fato não se prende só à sintaxe, mas ao campo também da fonética e da morfologia.

A flutuação na construção com pronomes relativos acompanhados ou não de preposições e artigos resulta da ser a sintaxe mais passível de "construções livres a soltas, de variações no sintagma e variação na disposição dos elementos no sintagma". (Camara , 1964, 195).

\section{Conclusão}

Os fatos aqui mencionados pertencem exclusivamente à categoria dos chamados vulgarismos. Apontam as tendências já contidas na deriva da língua, que irrompem quando o estrato social é o dito baixo, e/ou quando a situação é distensa.

Sabe-se que a fala popular apresenta características opostas: traços arcaizantes e novos desenvolvimentos. Estes se processam, habitualmente, no sentido rigoroso da deriva que pode assim ser observada no seu desenrolar. 
Dossiê Temático: Cultura, Civilização e Cidadania

\section{Referências}

Camara, Jr., J. Mattoso. Princípios de linguística geral. 4a . ed. Rio do Janeiro: Liv. Acadêmica, 1964,

- Dispersos. Seleção e introdução por Carlos Eduardo Falcão Uchoa. $2^{\mathrm{a}}$. ed. Rio de Janeiro: Fundação Getúlio Vargas. INDOC, 1975.

Cintra, Luis F. LindIey, Estudos de dialetologia portuguesa , Lisboa: Sá da Costa Editora, 1983.

Mattos e Silva, Rosa Virgínia. Sobre a mudança linguíística: uma revisão histórica. Separata do Boletim de Filologia, Tomo XXVI. Lisboa: Centro de Linguística da Universidade de Lisboa, 1980/81.

Rona, J. Pedro. Aspectos metodológicos de la dialectologia hispanoamericana, Montevideo: Mimo, 1958.

Cuervo,1960.

de Cartagena, Informes y comunicaciones. Bogotá: Inst. Care y

Silva Neto, Serafim da. Introdução ao estudo da língua portuguesa no Brasil. ${ }^{\mathrm{a}}$. ed. Rio de Janeiro: Presença, 1977.

- Os dados geográficos foram obtidos na Secretaria de Turismo da Prefeitura de Vassouras; os dados socio-culturais por pesquisa direta junto aos alunos. 